\title{
Perfil de cuidadores de idosos e percepção sobre saúde bucal
}

\author{
Nemre Adas Saliba' \\ Suzely Adas Saliba Moimaz ${ }^{2}$ \\ Jeidson Antônio Morais Marques 3 \\ Rosana Leal do Prado 4
}

SALIBA, N.A. ET AL. The profile of caregivers for the elderly and oral health perception. Interface - Comunic., Saúde, Educ., v.11, n.21, p.39-50, jan/abr 2007.

The aim of this study was to evaluate the profile and the oral health perception of caregivers for the elderly, who provide assistance to three benefit institutions in the city of Araçatuba, Brazil. A form was filled in by the interviewers in accordance with the answers given by 18 caregivers to questions about their knowledge of oral health. In relation to their educational background, $83.3 \%$ have a nursing assistant technical course qualification, whle $16.7 \%$ have no technical qualifications whatsoever. More than half of those interviewed $(61.11 \%)$ reported that they started working out of necessity, not for any particular affinity with the profession.. As to their knowledge of oral health, we detected a lack of information, with most of the caregivers needing more clarification about the most prevalent oral diseases. Many of them (55.56\%) believe that loss of teeth is part of the aging process. According to the results obtained, it was proved that caregivers need more information about oral health related to the elderly.

KEY WORDS: aged. caregivers. oral health.

O objetivo deste estudo foi avaliar o perfil e conhecimento sobre saúde bucal de profissionais cuidadores de idosos, que atuam em três asilos da cidade de Araçatuba. Foram entrevistados 18 cuidadores de três instituições, com o auxílio de um formulário, visando avaliar o grau de conhecimento destes quanto aos aspectos de saúde bucal. Em relação à formação escolar, 83,3\% desses profissionais possuem curso técnico de auxiliar de enfermagem e 16,7\% não apresentam qualquer tipo de formação técnica. Mais da metade dos entrevistados $(61,11 \%)$ relatou ter iniciado o trabalho por necessidade, não por afinidade. Quanto ao conhecimento em saúde bucal, detectou-se carência de informações, sendo que a maior parte necessita de esclar ecimento quanto aos problemas mais prevalentes que ocorrem na boca e muitos deles $(55,56 \%)$ acreditam que a perda dos dentes faz parte do envelhecimento. Constatou-se que os cuidadores precisam ser informados sobre aspectos de saúde bucal voltados para idosos.

PALAVRAS-CHAVE: idoso. cuidadores. saúde bucal.

${ }^{1}$ Professora, Programa de Pós-Graduação em Odontologia Preventiva e Social, Faculdade de Odontologia de Araçatuba, Unesp (FOA/Unesp), Araçatuba, SP. <nemre@foa.unesp.br>

2 Professora, Programa de Pós-Graduação em Odontologia Preventiva e Social, FOA/Unesp. <sasaliba@foa.unesp.br>

${ }^{3}$ Doutorando, Programa de Pós-Graduação em Odontologia Preventiva e Social, FOA/Unesp. <marques jam@hotmail.com>

${ }_{4}^{4}$ Mestranda, Programa de Pós-Graduação em Odontologia Preventiva e Social, FOA/Unesp. <rosanahb@yahoo.com.br>

${ }^{1}$ Programa de Pós-Graduação em Odontologia Preventiva e Social

Núcleo de Pesquisa em Saúde Coletiva - NEPESCO

Rua José Bonifácio, 1193.

Vila Mendonça - Araçatuba, SP

16.015-050 


\section{Introdução}

Com o aumento da expectativa de vida e diminuição da taxa de mortalidade, o envelhecimento populacional é um fenômeno mundial nos dias de hoje. Segundo dados do Instituto Brasileiro de Geografia e Estatística, a população brasileira com mais de sessenta anos em 2000 era de 14.536 .029 pessoas, representando um crescimento numérico de 3.813.324 pessoas em relação a 1991 (Brasil, 2005). Nessa perspectiva, em 2025, o Brasil será o sexto país do mundo em termos de população idosa, com mais de trinta milhões de habitantes acima de sessenta anos (Caldas, 1998; Saliba et al., 1999).

Com a configuração deste quadro, há necessidade da adaptação das políticas públicas de saúde, uma vez que, com o aumento no número de idosos, surgem novas necessidades de saúde que dependem de intervenções com alto custo para um cuidado especial (Caldas, 1998).

Alguns termos são utilizados para designar os idosos: "terceira idade", "melhor idade", "velhice". O termo "velho" ou "velhote", na França do século XIX, era utilizado para designar indivíduos que não possuíam bens ou eram indigentes. Aqueles que tinham certa posição social e que administravam seus bens desfrutavam de respeito e eram denominados de idosos, pois o termo "velho" era associado à decadência e incapacidade para o trabalho. Somente com a influência francesa é que o termo idoso passou a ser utilizado em documentos oficiais no Brasil, pois mesmo já existindo em nosso vocabulário, o termo não era utilizado (Gonçalves, 2002).

A Organização Mundial de Saúde (OMS) estabelece que um país pode ser considerado envel hecido quando o contingente de gerontes ultrapassa $7 \%$ de sua população total. Hoje, o Brasil já conta com 8,2 milhões de pessoas acima de sessenta anos (WHO, 2005), que representam 4,4\% de sua população (Brasil, 2005).

Com o avançar da idade, surgem sensíveis alterações no estilo de vida da população idosa, seja por problemas de saúde ou, mesmo, pelo processo fisiológico de envelhecimento, que se configura como um processo múltiplo e desigual de comprometimento e decadência das funções que caracterizam o organismo vivo em função do tempo de vida (Caldas, 1998). Essas mudanças levam os idosos, em muitos casos, a necessitar de alguém para auxiliá-los em atividades que antes pareciam de simples execução. Dessa necessidade surge a figura de cuidador de idosos que, em muitos casos, passa-nos sob um olhar desatento e sem a devida capacitação, resultando em desgaste tanto para o ser cuidado, quanto para o cuidador.

O termo "cuidar" denota uma ação dinâmica, pensada, refletida; já o termo "cuidado" dá a conotação de responsabilidade e de zelo; portanto, o processo de cuidar é a forma como se dá o cuidado e é um processo interativo, que desenvolve ações, atitudes e comportamentos com base no conhecimento científico, na experiência, intuição e tendo como ferramenta principal o pensamento crítico, sendo essas ações e/ ou outros atributos realizados para o ser cuidado, no sentido de promover, manter e/ ou recuperar sua dignidade humana. O termo assistir parece ser uma ação mais passiva de observar, acompanhar, favorecer, auxiliar e proteger. Na verdade, a assistência não necessariamente inclui o "cuidar" (Santos, 2001). 
A palavra "cuidar" é um verbo transitivo indireto, implicando a existência de um sujeito agente e um objeto passivo. Quem cuida, trabalha pelos interesses de alguém e preocupa-se com este alguém. Além, é claro, da necessidade de atenção ao cuidado prestado, para que este não se transforme em algo automático e se perca de vista que, ali, recebendo cuidado, encontra-se um sujeito que tem uma dimensão existencial, sendo atingido pelos cuidados prestados pelo outro sujeito (Caldas, 2000).

Os cuidadores de idosos são pessoas que se dedicam à tarefa de cuidar de um idoso, podendo ser algum familiar: filho, sobrinho, neto, amigo, o chamado "cuidador informal" ou pessoas que, embora não tenham vínculo com o idoso, são contratadas para esse trabalho, o "cuidador formal" (Gonçalves, 2002). Os cuidadores têm assumido um perfil próprio e tarefas específicas e complexas que precisam ser desenvolvidas ou acompanhadas por pessoas habilitadas para o desempenho da assistência que o idoso precisa para manter o seu bem-estar.

Pouco se conhece sobre o perfil de cuidadores de idosos, suas necessidades, sua formação. A urgência de se estruturar uma equipe multidisciplinar qualificada com amplo conhecimento geriátrico e gerontológico é iminente, na busca da melhoria da qualidade de vida dos idosos institucionalizados. Dentro deste pensamento, a universidade pode realizar papel de agente transformador da qualidade da saúde de idosos, por meio da colaboração na formação dessa equipe.

Sabe-se que essa parcela da população requer uma atenção especial em função das condições sociais, mentais, físicas e afetivas nas quais vivem - em muitas das vezes, situações de total abandono social (Almeida et al., 2004). Portanto, pessoas que se enver edam por essa área de atuação, submetem-se, algumas vezes, a condições extremas de desgaste não só físico, como emocional. Por esta razão, é de grande importância uma boa formação técnica fundamentada não só em conceitos teóricos, mas também em aspectos humanos e éticos.

Este estudo se propôs a avaliar o conhecimento em saúde bucal de cuidadores de idosos, contratados, que atuam em três instituições de amparo ao idoso da cidade de Araçatuba, sendo elas: Lar da Velhice, Asilo São Vicente de Paulo e Abrigo Ismael.

\section{Metodologia}

Foram entrevistados 18 cuidadores, total existente nas três instituições beneficiadas com o Projeto de Extensão Universitária, coordenado pelo Departamento de Odontologia Infantil e Social da Faculdade de Odontologia de Araçatuba (FOA/ Unesp), intitulado "Promoção de Saúde em idosos institucionalizados da cidade de Araçatuba/SP", cujos objetivos incluem: promoção, prevenção e recuperação da saúde bucal dos internos.

De acordo com a metodologia proposta, optou-se pela entrevista dirigida, utilizando-se, para a coleta das informações, um formulário semi-estruturado, com 44 questões abertas e fechadas. As variáveis de estudo incluíram dados gerais: idade, escolaridade, sexo; conhecimento sobre saúde bucal: cárie, placa bacteriana, doença periodontal; hábitos de higiene oral: utilização de flúor e fio dental, realização de escovação dentária; rotina de hábitos de higiene bucal 
dos idosos: se é realizada a higienização, como é feita, sua importância; e percepção dos cuidadores quanto à própria saúde bucal e quanto à saúde bucal do idoso.

A entrevista foi gravada e teve tempo de duração de, aproximadamente, dez minutos, sendo obtido o termo de consentimento livre esclarecido dos participantes da pesquisa. Foi realizado um estudo-piloto, para validação e adequação do instrumento de coleta de dados. A modalidade da entrevista semi-estruturada "ao mesmo tempo em que valoriza a presença do investigador, oferece todas as perspectivas possíveis para que o informante alcance a liberdade e a espontaneidade necessárias, enriquecendo a investigação"; mantém a presença consciente e atuante do pesquisador e, ao mesmo tempo, permite a relevância na situação do ator.

As entrevistas foram realizadas por apenas um pesquisador. Cada entrevistado foi abordado em seu local de trabalho, entre 8-18 horas, durante os meses de setembro a novembro de 2005. As informações obtidas foram analisadas quantitativamente e, com base nas respostas dadas pelos entrevistados, foi elaborado um manual com informações em saúde bucal, para a orientação dos cuidadores na atenção aos idosos.

\section{Resultados e discussão}

A população em estudo apresentou idade média de 37,4 anos, sendo que a idade mínima foi de 24 e a máxima de sessenta anos, predominantemente do gênero feminino $(77,8 \%)$.

Em relação à formação escolar, 5,55\% não concluíram o primeiro grau, mais de $60 \%$ concluíram o segundo, $83,3 \%$ possuem curso técnico de auxiliar de enfermagem, e 16,7\% não apresentam qualquer tipo de formação técnica.

Os dados referentes a per cepção e hábitos dos cuidadores de idosos institucionalizados estão apresentados nas tabelas 1, 2 e 3.

Tabela 1. Respostas dos cuidadores sobre a motivação para início do trabalho no asilo e participação em treinamentos para cuidar de idosos, Araçatuba, 2005.

\begin{tabular}{|c|c|c|c|c|}
\hline \multirow{2}{*}{ Perguntas } & \multicolumn{2}{|c|}{ Sim } & \multicolumn{2}{|c|}{ Não } \\
\hline & $\mathbf{n}$ & $\%$ & $\mathbf{n}$ & $\%$ \\
\hline \multicolumn{5}{|l|}{ Motivação para início do trabalho nos asilos } \\
\hline Afinidade & 7 & 38,89 & - & - \\
\hline Necessidade & 11 & 61,11 & - & - \\
\hline Já participou de treinamentos para cuidar de idosos? & 4 & 22,22 & 14 & 77,78 \\
\hline
\end{tabular}

Tabela 2. Relação entre perda dentária e crença de que os dentes não duram a vida toda.

\begin{tabular}{|c|c|c|}
\hline & \multicolumn{2}{|c|}{ Você já perdeu algum dente? } \\
\hline & Sim & Não \\
\hline \multicolumn{3}{|l|}{ Você acha que os dentes duram a vida toda? } \\
\hline Sim & 5 & 2 \\
\hline Não & 8 & 3 \\
\hline Total & $13(72,2 \%)$ & $5(27,8 \%)$ \\
\hline
\end{tabular}

42 Inteface Comunic, Saúde, Educ, v.11, n.21, p.39-50, jan/abr 2007 
PERFIL DE CUIDADORES DE IDOSOS E PERCEPÇÃO ...

Tabela 3. Respostas dos cuidadores quanto ao processo de higiene bucal dos idosos institucionalizados, Araçatuba, 2005.

\begin{tabular}{|c|c|c|c|c|c|c|c|c|}
\hline \multirow{2}{*}{ Perguntas } & \multicolumn{2}{|c|}{ Sim } & \multicolumn{2}{|c|}{ Não } & \multicolumn{2}{|c|}{ Não sei } & \multicolumn{2}{|c|}{ Nem todos } \\
\hline & $\mathbf{n}$ & $\%$ & $\mathbf{n}$ & $\%$ & $\mathbf{n}$ & $\%$ & $\mathbf{n}$ & $\%$ \\
\hline Os idosos fazem a escovação e higienização da boca? & 18 & 100 & 0 & 0 & 0 & 0 & - & - \\
\hline $\begin{array}{l}\text { Você já teve a experiência de ter que realizar a } \\
\text { higienização bucal de algum idoso? }\end{array}$ & 16 & 88,89 & 2 & 11,11 & - & - & - & - \\
\hline Você já "examinou" (olhou) dentro da boca dos idosos? & 11 & 61,11 & 7 & 38,89 & - & - & - & - \\
\hline $\begin{array}{l}\text { Possui o hábito de examinar a boca dos idosos como } \\
\text { rotina? }\end{array}$ & 0 & 0 & 18 & 100 & - & - & - & - \\
\hline $\begin{array}{l}\text { As alterações bucais podem ser indicativas de que algo } \\
\text { no organismo não está bem? }\end{array}$ & 15 & 83,34 & 2 & 11,11 & 1 & 5,55 & - & - \\
\hline $\begin{array}{l}\text { Alguns idosos não possuem nenhum dente. Você acha } \\
\text { que eles vivem bem sem os dentes? }\end{array}$ & 4 & 22,22 & 14 & 77,78 & - & - & - & - \\
\hline $\begin{array}{l}\text { Os idosos ficam sem as próteses durante o sono (à } \\
\text { noite)? }\end{array}$ & 11 & 61,11 & 2 & 11,12 & 1 & $\begin{array}{r}5,55 \\
0\end{array}$ & $\begin{array}{l}4 \\
-\end{array}$ & 22,22 \\
\hline É feita a higienização das próteses dos idosos? & 18 & 100 & 0 & 0 & 0 & 5,55 & - & - \\
\hline É utilizado algum produto específico? & 11 & 61,12 & 6 & 33,33 & 1 & & & \\
\hline $\begin{array}{l}\text { Você acha que há possibilidade da transmissão de } \\
\text { alguma doença quando as próteses de vários idosos } \\
\text { são colocadas juntas em um mesmo recipiente } \\
\text { simultaneamente? }\end{array}$ & 18 & 100 & 0 & 0 & - & - & - & - \\
\hline
\end{tabular}

Os cuidadores foram questionados sobre a existência de processo de higienização bucal dos idosos, e foi unânime a resposta de que todos os idosos a realizam, porém nem todos são capazes de realizá-la sozinhos.

A população beneficiada pelo trabalho do cuidador, neste caso, o idoso institucionalizado, vive submetida a condições físicas, mentais e sociais, por vezes, delicadas e, em alguns casos, caracterizando um quadro de abandono social e afetivo. Ao profissional que opta por trabalhar com esses cidadãos é requerida sensibilidade social e um perfil voltado para as questões éticas e humanas, além da formação técnico-científica (Almeida et al., 2004).

$\mathrm{Na}$ análise dos resultados, chamou a atenção o fato de que uma das cuidadoras tinha sessenta anos e, portanto, é uma idosa cuidando de outros idosos.

De acordo com a literatura, o predomínio do sexo feminino, desempenhando papéis de cuidado com o idoso, tem sido constante. Isto pode ser atribuído ao fato de que a sociedade, por meio de sua cultura, imputa à mulher o papel de cuidar (Nakatani et al., 2003).

O grau de escolaridade é de extrema importância, uma vez que a falta deste pode interferir, direta ou indiretamente, na prestação de cuidados ao idoso. Há uma queda na qualidade do serviço prestado, pois o cuidador necessita seguir dietas, prescrições e manusear medicamentos (Nakatani et al., 2003).

Os cuidadores trabalham em média há 3,13 anos nas instituições, sendo que o cuidador que possui menos tempo de trabalho exerce essa atividade há três meses, o mais experiente há 11 anos (Figura 1 ) e mais da metade $(61,11 \%)$ relatou ter iniciado o trabalho na área por necessidade, não por afinidade (Tabela 1). Esta circunstância é preocupante devido ao fato de que a procura por essa atividade laborativa com ausência de afinidade pode comprometer a 
qualidade da assistência prestada ao idoso, além de aumentar os riscos de violência contra os internos. É necessário salientar, também, a necessidade de estímulos voltados a proporcionar um desempenho satisfatório do cuidador, para que o desenvolvimento de suas atividades não caia na chamada "rotina", e ele esqueça que, do outro lado, há um ser humano, passível de estímulos e sentimentos.

Figura 1 . Distribuição percentual dos cuidadores segundo tempo de trabalho nos asilos, Araçatuba, 2005.

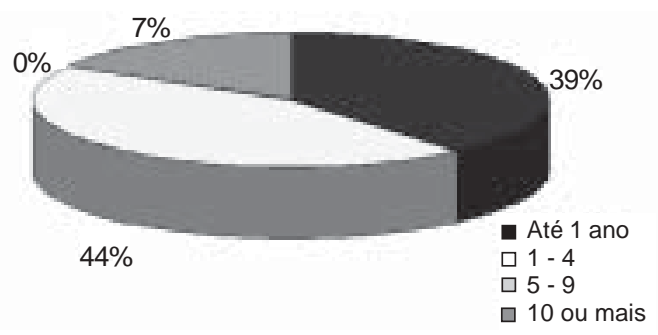

O tempo de trabalho do cuidador deve ser avaliado com cautela, uma vez que a atividade exercida por ele é deveras desgastante e a tar efa de cuidar de um adulto dependente implica riscos de tornar o cuidador doente e igualmente dependente (Cerqueira, 2002).

O relato da perda de, pelo menos, um elemento dentário por necessidade de extração foi presente em $72,2 \%$ dos entrevistados (Tabela 2 ), e nenhum deles classificou sua saúde bucal como ótima. Segundo Mello \& Padilha (2000), a percepção e as atitudes do cuidador em relação à própria saúde bucal influenciam no cuidado que este oferece para o idoso. Se o cuidador falha na conservação da sua higiene bucal, a tendência é que este transfira as mesmas ações para o idoso que está sob seus cuidados. Em muitos casos, a partir deste item, pode-se determinar a qualidade dos serviços prestados aos idosos.

Apesar de $83 \%$ dos cuidadores acreditarem que alterações bucais são indicativas de que alguma coisa no organismo não está bem, nenhum deles possui o hábito de examinar a boca dos idosos como rotina, e 38,89\% nunca o fizeram (Tabela 3). Não são poucas as alterações que decorrem do envelhecimento. Tratando-se de nível sistêmico, podemos citar perdas celulares, enfraquecimento do sistema músculo-esquelético e diminuição da capacidade funcional de muitos sistemas bioquímicos, o que leva o idoso a um prejuízo que só pode ser amenizado se o cuidador conseguir identificar este processo (Nakatani et al., 2003).

Quando se trata de alterações bucais decorrentes do envelhecimento, não se pode deixar de citar a diminuição da capacidade gustatória, decorrente de uma diminuição no número de papilas gustativas (cerca de $80 \%$ a menos do que na idade adulta). Os dentes adquirem coloração mais escurecida, e, por vezes, 
PERFIL DE CUIDADORES DE IDOSOS E PERCEPÇÃO ...

podem apresentar-se desgastados devido ao uso de dentifrícios contendo agentes abrasivos. O periodonto tende a ficar mais frágil, sofrendo reabsorções, com conseqüente migração apical da gengiva, expondo as raízes dentais. 0 idoso costuma queixar-se de "ar dência", "queimação" ou mesmo de dores na mucosa bucal. Este fato pode estar ligado diretamente à diminuição do fluxo salivar (xerostomia), também inerente ao envelhecimento que, por sua vez, pode ser acentuada pelo uso de medicamentos. Este desconforto ainda pode estar sendo provocado por próteses totais ou parciais, dentes fraturados, ingestão de alimentos com arestas cortantes, entre outros fatores (Brunetti, 2002).

Quanto aos conhecimentos em saúde bucal, 66,6\% dos cuidadores acreditam que cárie não é doença, $22,2 \%$ disseram que era doença, $11,1 \%$ não souberam responder, e 55,56\% dos entrevistados afirmaram que a perda dos dentes na terceira idade é um processo inevitável (Tabela 4).

Tabela 4. Respostas dos cuidadores sobre o conhecimento e hábitos de higiene em saúde bucal, Araçatuba, 2005.

\begin{tabular}{|c|c|c|c|c|c|c|}
\hline \multirow{2}{*}{ Perguntas } & \multicolumn{2}{|c|}{ Sim } & \multicolumn{2}{|c|}{ Não } & \multicolumn{2}{|c|}{ Não sei } \\
\hline & $\mathbf{n}$ & $\%$ & $\mathbf{n}$ & $\%$ & $\mathbf{n}$ & $\%$ \\
\hline Você acha que os dentes duram a vida toda? & 7 & 38,89 & 10 & 55,56 & 1 & 5,55 \\
\hline Cárie é doença? & 4 & 22,22 & 12 & 66,66 & 2 & 11,12 \\
\hline O flúor é importante para a prevenção da cárie? & 16 & 88,88 & 0 & 0 & 2 & 11,11 \\
\hline Você usa flúor? & 10 & 55,55 & 8 & 44,45 & - & - \\
\hline Você sabe o que é placa bacteriana? & 6 & 33,33 & 12 & 66,67 & - & - \\
\hline Sua gengiva já sangrou espontaneamente alguma vez? & 7 & 38,88 & 11 & 61,12 & - & - \\
\hline $\begin{array}{l}\text { Alguma vez você foi ensinado sobre como escovar os } \\
\text { dentes? }\end{array}$ & 17 & 94,45 & 1 & 5,55 & - & - \\
\hline E a usar fio dental? & 16 & 88,88 & 2 & 11,12 & - & - \\
\hline
\end{tabular}

Mello \& Padilha (2000) relatam que cuidadores e inclusive cirurgiões-dentistas, tendem a ter pouca perspectiva em relação à longevidade do idoso e a questionar a preocupação com a manutenção dos dentes na cavidade bucal. Atitudes como esta podem ser tomadas como negligência extrema e contribuem para a deficiência na qualidade da saúde bucal e geral dos idosos, definindo sua capacidade mastigatória, de nutrição, fonética e de socialização.

Quanto a métodos de prevenção da cárie dentária, 88,88\% relataram ser bastante importante o uso de flúor, porém $44,44 \%$ disseram que não fazem utilização dele. Já quando questionados se haviam sido ensinados a escovar os dentes, $94,44 \%$ responderam afirmativamente e $11,12 \%$ relataram nunca ter recebido orientações relativas ao uso do fio dental (Tabela 4).

Apesar de grande parte dos cuidadores acreditar ser o flúor importante para a prevenção da cárie dentária, quase metade $(44,44 \%)$ dos entrevistados disseram não fazer uso deste (Tabela 4). Esse dado reflete o desconhecimento quanto às fontes de flúor, como, por exemplo, o creme dental e a água de abastecimento. 
Ainda tratando de conhecimentos em saúde bucal, 66,67\% disseram não saber o que é placa bacteriana e quando questionados se já havia ocorrido sangramento em suas gengivas durante o processo de higiene bucal, 38,89\% dos entrevistados responderam afirmativamente. Esses dados demonstram a carência de informação em saúde bucal por parte da população, especialmente por indivíduos que lidam com o cuidado a pessoas dependentes, carentes e, muitas vezes, fragilizadas, cujo conhecimento em saúde é de extrema importância para a longevidade com qualidade de vida.

Pucca Júnior (2000) salienta que a saúde bucal é parte integrante e inseparável da saúde geral dos indivíduos e tem sido relegada ao completo esquecimento, no caso brasileiro, quando se discutem as condições de saúde da população idosa. Ele ainda relata, em suas pesquisas, que a perda total dos dentes é aceita pela sociedade e pelos cirurgiões-dentistas como algo normal e natural com o avançar da idade, levando a uma falsa concepção do processo de envelhecimento. Vale salientar que esse processo, por si só, não traz doenças, estas podem ou não ocorrer.

Moimaz et al. (2004a) afirmam que, no Brasil, a cárie dentária e a doença periodontal são problemas prioritários quando se trata de saúde bucal, pois além de atingirem a quase totalidade da população, ambas apresentam altos índices de prevalência e incidência.

Os idosos podem ser classificados dentro de três grupos distintos, de acordo com sua habilidade funcional: independentes - constituído por idosos sadios; parcialmente dependentes - idosos com problemas físicos e/ ou psicológicos parcialmente debilitantes; totalmente dependentes - idosos com problemas físicos e/ ou psicológicos totalmente debilitantes (Guedes, 2001). De acordo com isso, deve ser permitido e estimulado, a idosos que têm capacidade de realizar sua própria higiene bucal, que eles mesmos a façam, pois dessa forma estarão exercitando sua coordenação motora e, também, elevando sua autoestima.

Boa parte dos entrevistados (88,88\%) já haviam realizado a higiene bucal dos idosos ao menos uma vez e $77,77 \%$ acr editam que os idosos totalmente desdentados não vivem bem.

A perda dos dentes implica tanto questões psicológicas, comprometendo a auto-estima, quanto questões de ordem de saúde geral. De acordo com Moriguchi (1998), “a perda da dentição influi sobre a mastigação, digestão, gustação, pronúncia, aspecto estético e predispõe a doenças geriátricas". Dentro deste quadro, a opinião expressa pela maioria dos cuidadores $(77,78 \%)$ em relação ao estilo de vida dos idosos totalmente desdentados reflete a realidade deletéria dessa condição.

Os cuidadores relataram, em $61,11 \%$ das respostas, que os idosos dormem sem as próteses; em $11,12 \%$, que eles não a tiram para dormir e em $22,22 \%$ das respostas, que alguns a removem antes do sono e outros não.

$\mathrm{Na}$ literatura, há divergências quanto à utilização ou não de próteses durante o período de sono. Saliba et al. (2001), no Manual para conservação e higienização de próteses dentárias, afirmam a necessidade de retirada da prótese da cavidade bucal por, no mínimo, oito horas diárias, buscando a recuperação e possibilidade da realização de higienização dos tecidos bucais. Já jitomirski \& Jitomirski (1997) relatam que, se os idosos desejarem dormir com 
PERFIL DE CUIDADORES DE IDOSOS E PERCEPÇÃO ...

as próteses, podem fazê-lo. E justamente esta prática foi encontrada em um dos asilos, no qual a quase totalidade dos cuidadores relataram que as próteses só são removidas dos idosos que assim desejam.

Todos os entrevistados afirmaram ser realizada a higiene bucal das próteses dos idosos; $61,11 \%$ dos cuidadores relataram ainda utilizar algum produto específico (Tabela 3), geralmente hipoclorito (44,45\%); 33,33\% (Tabela 5) relataram não utilizar produto algum além de creme dental.

Tabela 5. Tipo de produto usado durante o processo de higienização das próteses dos idosos, Araçatuba, 2005.

\begin{tabular}{lcc}
\hline Tipo de produto & $\mathbf{n}$ & $\%$ \\
\hline Hipoclorito & 8 & 44,45 \\
Creme dental & 6 & 33,33 \\
Não sabe & 4 & 22,22 \\
\hline
\end{tabular}

Essa unanimidade quanto à realização da higiene das próteses dos idosos é importante, pois denota que, mesmo não sendo realizada de maneira correta, a higienização não é negligenciada. A limpeza das próteses totais deve ser feita após cada refeição, com a utilização de escova e sabão neutro. O uso de creme dental deve ser evitado por conter agentes abrasivos e causar desgaste à resina da prótese. Uma ou duas vezes por semana deve-se mergulhar a prótese durante 15 minutos em solução contendo $220 \mathrm{ml}$ de água e uma colher (chá) de hipoclorito de sódio a 2\% (Saliba et al., 2001).

Quando questionados sobre a possibilidade da transmissão de doenças durante a higienização de próteses de diferentes idosos em um mesmo recipiente, simultaneamente, foi unânime a resposta de que há a possibilidade de contaminação. Essa percepção é importante, tendo em vista estudo anterior de Saliba et al. (1999), que constataram serem $50 \%$ dos idosos dessas três instituições portadores de algum tipo de prótese. Em outro estudo realizado por Moimaz et al. (2004b), no município de Piacatu/ SP, da amostra estudada, $90 \%$ eram portadores de próteses totais. Mesmo que a amostra estudada não corresponda a idosos institucionalizados, é importante que esteja difundida a noção de higienização dessas próteses, pois, se feita de forma inadequada, acondicionando próteses de diferentes pessoas em um mesmo recipiente simultaneamente, dissemina-se um processo de infecção cruzada.

Mello \& Padilha (2000) lembram que a maioria dos idosos não consegue manter bons níveis de higiene bucal ou de suas próteses necessitando, em muitos casos, do auxílio do cuidador para realizá-la. Então, é indispensável o conhecimento sobre o processo correto de higiene de próteses, pois se configura um cuidado diário e fundamental para a manutenção da saúde bucal do idoso.

Constatou-se, ainda, que, apesar de 77,7\% já terem participado de treinamento sobre o cuidado com idoso, a maioria nunca recebeu orientação sobre cuidados bucais na terceira idade (Tabela 1 ). 


\section{Conclusão}

A própria condição bucal influencia no tipo de cuidado prestado ao idoso. Portanto, é importante que os cuidadores sejam motivados a destinar à saúde bucal o cuidado que a ela é devido, para que possam priorizar o cuidado à saúde bucal dos idosos.

Pôde-se verificar que não há supervisão de saúde bucal nas instituições estudadas, talvez por falta de capacitação dos cuidadores ou por atribuição de prioridade equivocada a questões de saúde. A falta de informação sobre saúde bucal pode ser apontada como uma das responsáveis pela carência de ações no cuidado prestado por parte dos cuidadores, sendo necessária a capacitação destes para lidar com idosos, pois, durante o processo de contratação não são exigidos, pré-requisitos relativos à formação.

Diante disso, convém assinalar que cuidadores, quando capacitados, podem reduzir o desconforto sentido pelo idoso nos diversos casos citados e até mesmo evitar que processos graves de doenças se instalem, proporcionando melhor qualidade de vida.

O desenvolvimento de novas pesquisas nesta área de conhecimento faz-se necessário, uma vez que publicações são escassas neste campo de atuação de profissionais da saúde.

Todos os autores participaram, igualmente, da elaboração do artigo, sua discussão, redação e revisão. R.L. Prado e J.A.M. Marques participaram da coleta de dados realizadas junto às instituições asilares. 
PERFIL DE CUIDADORES DE IDOSOS E PERCEPÇÃO ...

\section{Referências}

ALMEIDA, M.E.L.; MOIMAZ, S.A.S.; GARBIN, C.A.S.; SALIBA, N.A. Um olhar sobre o idoso: estamos preparados? Rev. Fac. Odontol., v.45, n.1, p.64-8, 2004.

BRASIL. Instituto Brasileiro de Geografia e Estatística. Censo Populacional. Disponível em: <http:// www.ibge.gov.br>. Acesso em: 27 set. 2005.

BRUNETTI, R.; BRUNETTI, F.L. Odontogeriatria: noções de interesse clínico. São Paulo: Artes Médicas, 2002.

CALDAS, C.P. A dimensão existencial da pessoa idosa e seu cuidador. Textos Envelhecimento, v.3, n.4, 2000. Disponível em: <http://www.unati.uerj.br/tse/uerj>. Acesso em: 12 out. 2005.

CALDAS, C.P. A saúde do idoso: a arte de cuidar. Rio de Janeiro: Ed. UERJ, 1998.

CERQUEIRA, A.T.A.R. Programa de apoio a cuidadores: uma ação terapêutica e preventiva na atenção à saúde dos idosos. Psicol. USP, v.13, n.1, 2002. Disponível em: <http://www.scielo.br/scielo.php>. Acesso em: 09 out. 2005.

GONÇALVES, L.O. Cuidadores primários familiares dos idosos atendidos na Clínica Escola de Fisioterapia da Universidade do Vale do Itajaí - UNIVALI. 2002. Dissertação (Mestrado) - Universidade Federal de Santa Catarina, Florianópolis. 2002.

GUEDES, J.S. Sorria toda vida, viva com saúde bucal: autocuidados e cuidadores. São Paulo: Secretaria da Saúde de São Paulo, 2001. Disponível em: <www.saude.sp.gov.br>. Acesso em: 10 out. 2005.

JITOMIRSKI, F.; JITOMIRSKI, S. O que os cuidadores de idosos precisam saber sobre saúde bucal. Curitiba: Secretaria do Estado da Saúde do Paraná, 1997.

MELLO, A.L.F.; PADILHA, D.M.P. Instituições geriátricas e negligência odontológica. Rev. Fac. Odontol., v.41, n.1, p.44-8, 2000.

MOIMAZ, S.A.S.; GULINELLI, J.L.; GARBIN, C.A.S.; SPINELLI, E.B.; SALIBA, O. Avaliação do programa de promoção de saúde bucal para pré-escolares. RPG - Rev. Pós Grad., v.11, n.2, p.182-8. 2004a.

MOIMAZ, S.A.S.; SANTOS, C.L.V.; PIZZATTO, E.; GARBIN, C.A.S.; SALIBA, N.A. Perfil de utilização de próteses totais em idosos e avaliação da eficácia de sua higienização. Ciênc. Odontol. Bras., v. 7, n.3, p.728. 2004b.

MORIGUCHI, Y. Aspectos geriátricos no atendimento odontológico. Rev. Odont. Mod., v.19, n.4, p.11-3, 1998.

NAKATANI, A.Y.K.; SOUTO, C.C.S.; PAULETTE, L.M.; MELO, T.S.; SOUZA, M.M. Perfil dos cuidadores informais de idosos com déficit de autocuidado atendidos pelo Programa de Saúde da Família. Rev. Eletrôn. Enferm., v.5, n.1, 2003. Disponível em: <http:/www.fen.ufg.br/revista>. Acesso em: 10 out. 2005.

PUCCA JÚNIOR, G.A. A saúde bucal do idoso: aspectos demográficos e epidemiológicos. Disponível em: <http://odontologia.com.br/artigos.asp>. Acesso em: 30 out. 2005.

SALIBA, C.A.; SALIBA, N.A.; MARCELINO, G.; MOIMAZ, S.A.S. Auto-avaliação de saúde na terceira idade. Rev. Gaúcha Odontol., v.47, n.3, p.127-30, 1999.

SALIBA, N.A.; MOIMAZ, S.A.S.; GARBIN, C.A.S.; BRANDÃO, I.G.; CASTILHO, A.P. Manual para conservação e higienização de próteses dentárias. Araçatuba: FOA - Unesp, 2001.

SANTOS, S.S.C. Desenvolvimento sustentável e cuidado ao idoso. Textos Envelhecimento, v.3, n.6, 2001. Disponível em: <http://www.unati.uerj.br/tse/uerj>. Acesso em: 12 out. 2005.

WHO. WORLD HEALTH ORGANIZATION. Global movement for active ageing. Disponível em: <http:// www.who.int>. Acesso em: 29 out. 2005. 
SALIBA, N.A. ET AL.

SALIBA, N.A. ET AL. Perfil de los cuidadores de ancianos y percepción sobre la salud bucal. Interface - Comunic., Saúde, Educ., v.11, n.21, p.39-50, jan/abr 2007.

El objetivo de este estudio fue evaluar el perfil y el conocimiento sobre la salud bucal de los dieciocho cuidadores de ancianos que actúan en tres instituciones de beneficencia de la ciudad de Araçatuba. Fueron entrevistados todos los cuidadores, con el auxilio de un formulario, para evaluar el grado de conocimiento de los mismos respecto a los aspectos de la salud bucal. En relación a la formación escolar, el 83,3\% poseen curso técnico de auxiliar de enfermería. Más de la mitad $(61,11 \%)$ relató haber iniciado el trabajo por necesidad. En lo que respecta al conocimiento sobre salud bucal, se detectó la carencia de informaciones, siendo que la mayor parte necesita de informaciones sobre los problemas predominantes que ocurren en la boca, y muchos de ellos $(55,56 \%)$ creen que la pérdida de los dientes hace parte del envejecimiento. Se constató que los cuidadores necesitan ser instruidos sobre la salud bucal de los ancianos.

PALABRAS CLAVE: anciano. cuidadores. salud bucal. 